\title{
Knowledge and attitudes on HIV/AIDS and sexual behaviour among male soldiers in Sri Lanka Army
}

\author{
Saveen Semage ${ }^{1 *}$, Sujatha Samarakoon ${ }^{2}$ \\ From $16^{\text {th }}$ International Symposium on HIV and Emerging Infectious Diseases \\ Marseille, France. 24-26 March 2010
}

\section{Introduction}

HIV/AIDS can pose a threat to military preparedness and cohesion. Military in Sri Lanka too experience a very favourable environment for risk behaviours.

\section{Objectives}

To assess knowledge and attitudes on HIV/AIDS and sexual behaviour among male soldiers in Sri Lanka Army.

\section{Methods}

A cross sectional descriptive study was conducted among 600 soldiers selected using multi stage random sampling and a self administered questionnaire was used to collect information during the month of August 2007. Level of knowledge was decided using inter quartile range $\left(25^{\text {th }}\right.$ centile was considered as poor knowledge) and attitudes were assessed on a likert scale.

\section{Results}

Response rate was 99.5\% ( $\mathrm{n}=597)$. A majority $(88.6 \%$; $\mathrm{n}=447)$ had completed education up to GCE O/L. Level of knowledge on HIV/AIDS was satisfactory in $57.1 \%(\mathrm{n}=341)$. A statistically significant association of satisfactory knowledge on HIV/AIDS was observed with an educational level of $\geq$ GCE A/L $(p<0.001)$ and period of military service of $>10$ years $(p=0.03)$ but not with area of service and age.

A majority of soldiers $(55.7 \% ; \mathrm{n}=333)$ had desirable attitudes towards HIV/AIDS which was significantly associatedwith an educational level of $\geq$ GCE A/L ( $p<$ 0.001 ) but not with age, period of military service or area of service.

Ninety percent $(n=498)$ of them were currently sexually active. Nearly half $(47.7 \% ; n=259)$ had their sex debut before 20 years of age A majority $(80.2 \%$; $\mathrm{n}=$ $481)$ have had premarital sex and $45 \%(n=238)$ of currently sexually active soldiers reported having non regular sexual partners during last 12 months. Prevalence of consistent condom use with a non regular partner was only $21.8 \%(n=52)$ where as only $37 \%(n=88)$ had used a condom at the most recent sexual contact with a non regular partner. Reasons for not using were mainly perception of invulnerability $(62.7 \% ; \mathrm{n}=94)$ and non availability $(24 \% ; n=36)$. Lifetime homosexual experience was $19.6 \%(\mathrm{n}=99)$. About one third $(32.1 \%$; $\mathrm{n}=$ 190) had not had any educational exposure on HIV/ AIDS.

\section{Discussion}

Marginal level of knowledge (57.1\%) and risky sexual behaviour existing among soldiers would create a conducive environment to trigger a possible epidemic endangering the general population too.

\section{Author details \\ ${ }^{1}$ Sri Lanka Army Medical Services, Colombo, Sri Lanka. ${ }^{2}$ National STD/AIDS Control Program, Ministry of Healthcare \& Nutrition Sri Lanka, Colombo, Sri} Lanka.

Published: 11 May 2010

doi:10.1186/1742-4690-7-S1-P117

Cite this article as: Semage and Samarakoon: Knowledge and attitudes on HIV/AIDS and sexual behaviour among male soldiers in Sri Lanka Army. Retrovirology 2010 7(Suppl 1):P117.

* Correspondence: saveen70@yahoo.com

${ }^{1}$ Sri Lanka Army Medical Services, Colombo, Sri Lanka 